\title{
A System to Test the Effects of Materials on the Electron Drift Lifetime in Liquid Argon and Observations on the Effect of Water
}

\author{
R. Andrews, W. Jaskierny, H. Jöstlein, C. Kendziora, S. Pordes*, T. Tope \\ Particle Physics Division, Fermi National Accelerator Laboratory, Batavia, Illinois, 60510, \\ $U S A$
}

\begin{abstract}
A materials test system (MTS) has been developed at FNAL to assess the suitability of materials for use in a large liquid argon time projection chamber. During development of the MTS, it was noted that controlling the cryostat pressure with a 'raining' condenser reduced the electron drift lifetime in the liquid argon. The effect of condensing has been investigated using a series of passive materials to filter the condensate. We report the results of these studies and of tests on different candidate materials for detector construction. The inferred reduction of electron drift lifetime by water concentrations in the parts per trillion is of particular interest.
\end{abstract}

Key words: LArTPC, Liquid Argon, Purity, Water, Electron Drift Lifetime

\section{Introduction}

Liquid argon time projection chambers (LArTPCs) offer an opportunity for novel neutrino physics $[1,2]$. They can provide bubble-chamber quality event images by drifting ionization electrons created by the passage of charged particles through the liquid to readout planes. Since argon is cheap and plentiful, one can conceive of detectors with multi-kiloton active volumes. A principal challenge for large LArTPCs is the removal of electronegative impurities that capture the ionization electrons. The Materials Test System (MTS) has been built at FNAL to develop liquid argon purification techniques [3] and to qualify materials for use in a large LArTPC by measuring their effect on the electron drift lifetime. A photograph of the MTS is included as Figure 1 and a schematic of the MTS cryostat is included as Figure 2.

\footnotetext{
* Corresponding author

Email address: stephen@fnal.gov (S. Pordes)
} 


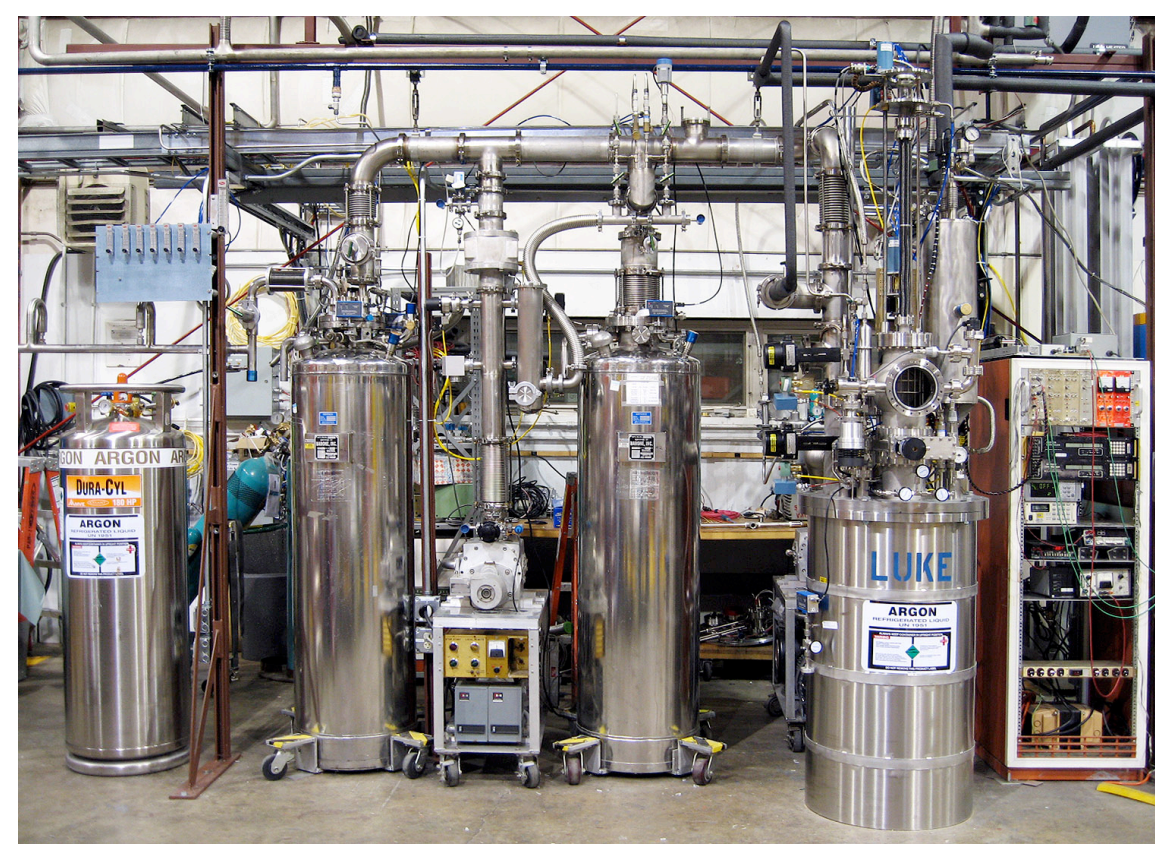

Figure 1: Photograph of the materials test system (MTS) at FNAL. Commercial argon (left) is passed through two filters (center) before entering the cryostat (right).

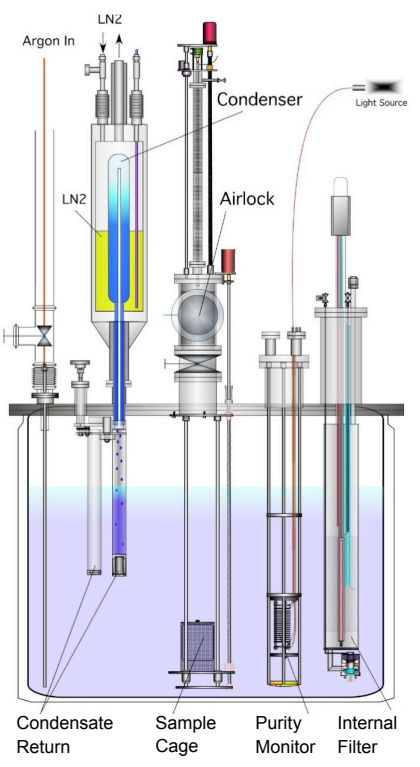

Figure 2: Schematic of the materials test system (MTS) cryostat at FNAL. 


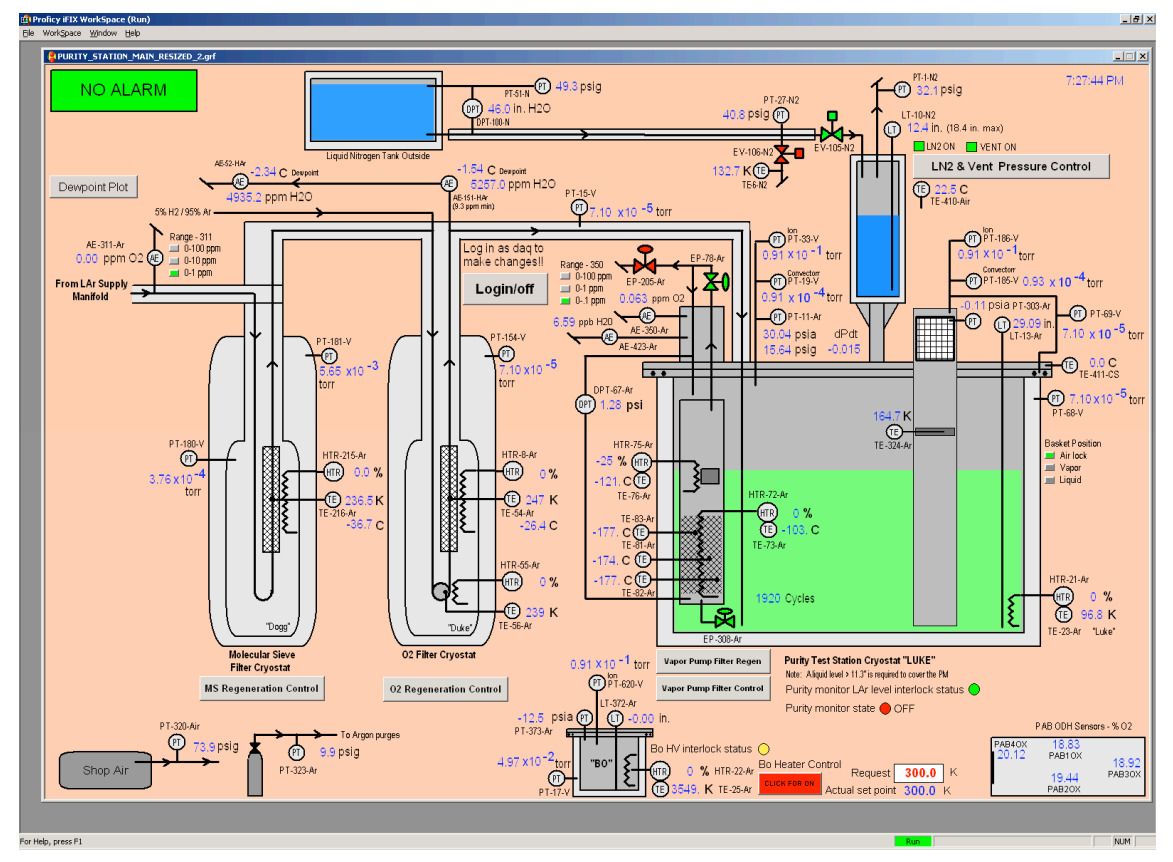

Figure 3: The iFIX graphical user interface for the MTS controls.

\section{The Materials Test System}

The Materials Test System has two major physical components - the argon source, a single-pass system that provides clean argon from commercial argon dewars, and the MTS cryostat in which the electron drift lifetime and other quantities are measured. The components used in the construction of the MTS are listed in [4]. The supply piping conforms to ASME B31.3 and the cryostat conforms to ASME Section VIII DIV 1.

The MTS controls are automated using a Beckhoff Programmable Logic Controller (PLC). The PLC reads out pressure, liquid level, temperature, and gas analysis instrumentation. Based upon the monitored instrument values, the PLC performs tasks such as opening and closing valves to control cryostat pressure, and sounding alarms that alert operators of undesirable conditions. The PLC communicates with iFIX software run on a Windows PC. The iFIX software allows entry of temperature and pressure set points and other operational parameters, displays real-time instrument values, and archives instrument values for historical viewing. The iFIX graphical user interface is shown as Figure 3.

Operation of the MTS involves evacuating the cryostat to $\approx 10^{-6}$ torr, filling it with clean argon, inserting a sample material, and monitoring the electron drift lifetime. Upon evaluation, the sample is removed and another sample can be inserted without changing the argon load. The condenser and internal filter are operated as needed. 


\subsection{Argon Source}

Commercial argon [5] is passed through a molecular sieve [6] to remove water and then activated copper [7] to remove oxygen and other electronegative impurities before entering the MTS cryostat. The liquid argon is supplied through vacuum-jacketed $\frac{3}{8}$ inch diameter tubing that consists of both stainless steel and copper sections. Small diameter tubing was chosen to limit the system throughput to match the capacity of the cryostat relief valve. The molecular sieve and activated copper filter material are each housed in $2 \frac{3}{8}$ inch diameter stainless steel tubing capped with ConFlat flanges. All valves in the delivery system are metal seal to atmosphere to prevent the diffusion of oxygen through o-ring or stem packing seals. Piping relief valves with o-ring seals have an argon purge on the exhast to prevent diffusion of ambient oxygen. This setup provides liquid argon with an electron drift lifetime of many milliseconds [8].

\subsection{MTS Cryostat}

The MTS cryostat is a 250 liter vacuum-insulated vessel with a working pressure of up to $35 \mathrm{psig}$. It is equipped with a liquid nitrogen-powered condenser that allows it to operate as a closed system. The cryostat itself contains the lifetime monitor, an active filter, a set of selectable return paths for the condensed argon, and a mechanism that allows materials to be inserted and removed from the cryostat.

\subsubsection{Internal Filter}

This novel filter sits in the MTS cryostat and contains a combination of molecular sieve and activated copper. It is used to maintain the purity of liquid argon in the cryostat and also to remove impurities introduced during materials testing. A description of filter operation can be found in [3].

\subsubsection{Lifetime Monitor}

Modeled after the 'purity' monitors of the ICARUS Collaboration [8, 9], this device allows for the direct measurement of the electron drift lifetime.

\subsubsection{Condenser to Control Cryostat Pressure}

Argon vapor enters the condenser through a central tube and contacts surfaces cooled with liquid nitrogen. The nitrogen is maintained at 50 psia to prevent argon from freezing on the contact surface. The condensed argon flows down the condenser walls and drips into one of four return paths before entering the bulk liquid. When the condenser is not operating, argon is continuously vented. A closed system is desirable during materials testing so that materialintroduced impurities are not removed by venting and their effect on the electron drift lifetime can be observed. 


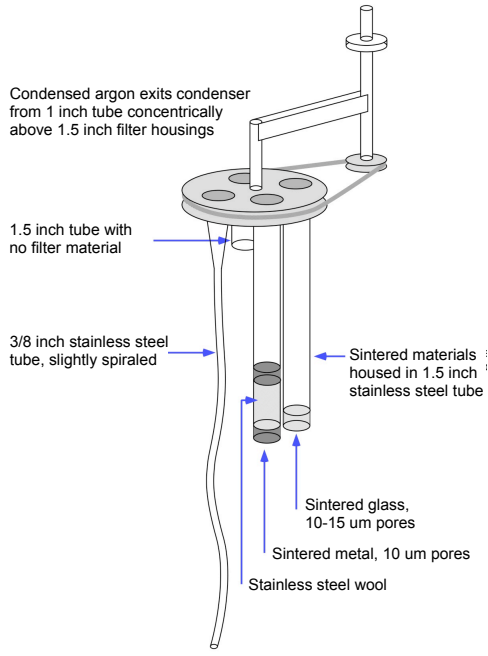

Figure 4: Detail of return mechanism. The return mechanism contains four return paths: a thin tube, a tube that contains a sintered glass disk at its end, a tube that contains steel wool and sintered metal, and a stub with no filter media. The thin tube extends approximately 36 inches into the cryostat, which has a depth of 40 inches. The tubes for the sintered metal and sintered glass extend approximately 20 inches into the cryostat. A handwheel, fed through the top flange of the cryostat, is used to select the return path into which condensate drips.

\subsubsection{Return Paths for Condensed Argon}

A wheel below the condenser allows the selection of a return path for the condensate. There are four paths available: a $1 \frac{1}{2}$ inch diameter tube with stainless steel wool enclosed by sintered metal, a similar tube with a disk of sintered glass at the end, a thin spiral tube, and a hole which allows the condensate to fall directly into the bulk liquid. Figure 4 shows details of this system. Other return paths, described in Section 3.1, were used briefly.

\subsubsection{Mechanism for Material Insertion and Removal}

An airlock, separated from the cryostat by a large gate valve, sits above the cryostat. The sample material is placed into a cage inside the airlock and prepared for insertion by evacuation or by purging with clean argon gas from the cryostat. The gate valve is then opened and the cage lowered into the cryostat via a rod attached to the top of the cage. Once in the cryostat, the cage is set on a lift platform. The rod is then released from the cage and retracted, allowing the gate valve to be closed. The cage is then lowered further into the cryostat. An RTD attached to the lift platform is used to indicate the temperature of the sample. Material removal involves raising the sample cage, opening the gate valve, attaching the rod to the cage, and raising the cage into the airlock. Once the gate valve is closed, the tested sample can be removed and another sample prepared. 


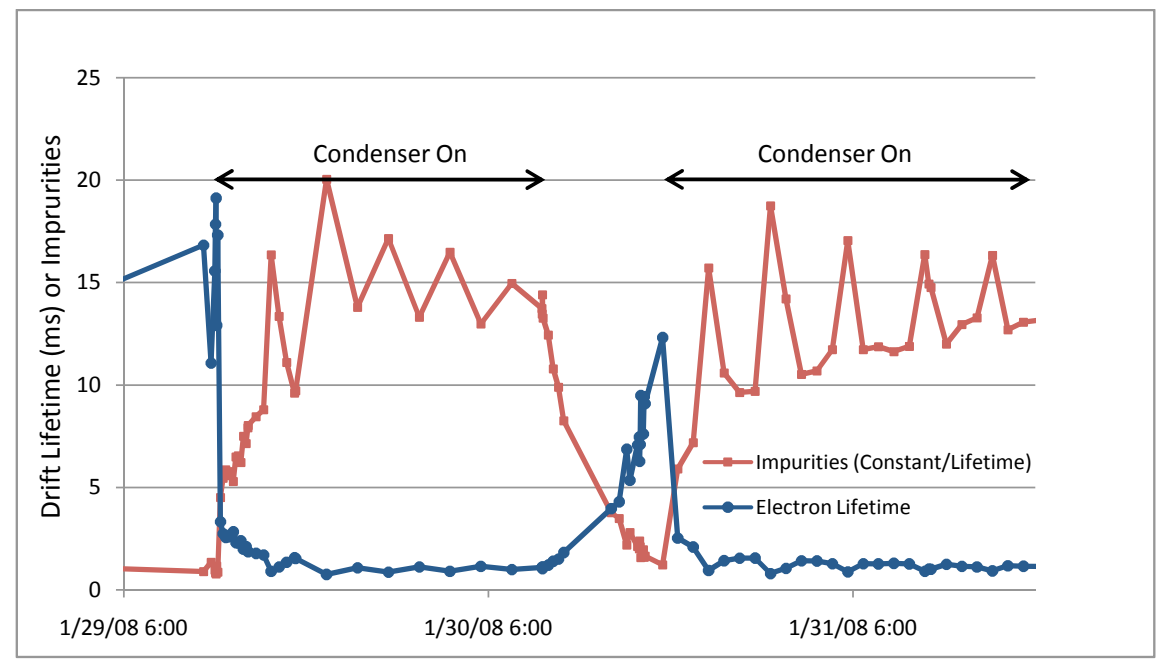

Figure 5: Effect of condenser operation on electron drift lifetime. The impurities, defined as a constant divided by the drift lifetime, represent the physical contaminants in the argon. When the condenser is off, the drift lifetime approaches $20 \mathrm{~ms}$; when the condenser is on, the lifetime quickly degrades to $1 \mathrm{~ms}$ or less. The oscillations in the drift lifetime are related to cycling of the condenser.

The MTS airlock has the ability to prepare materials for insertion by purging with argon because it may not be possible to evacuate the cryostat of a future large LArTPC. Samples can also be subject to evacuation, but this procedure is not routinely used since evacuation might remove contaminants that would not be removed by purging.

\subsubsection{Data Acquisition}

The data acquisition system for the lifetime monitor consists of a Visual Basic program run on a Tektronix 5054NV digital oscilloscope. The system is fully automated and takes measurements at a user-specified interval. A communication program sends the lifetime data to the iFIX interface where it is stored with the MTS system information.

\section{Effect of Condenser Operation on Electron Drift Lifetime}

After many millisecond electron drift lifetimes were obtained at FNAL with an open system [8], the condenser was first used to control the MTS cryostat pressure in January 2008. The condensate was allowed to drip directly into the bulk liquid and it immediately became clear that condensing reduced the electron drift lifetime dramatically, from ten milliseconds to less than one millisecond, as shown in Figure 5. 


\subsection{Characterization of Condensing-Associated Impurities}

Since the cryostat had been evacuated to below $10^{-6}$ Torr and there was little material in the vapor space of the cryostat other than the three coaxial lifetime monitor cables, it did not seem likely that condensing introduced chemical impurities from the vapor space into the liquid. It was initially thought that the decrease in drift lifetime was caused by argon ions that formed as the condensate dripped from the metal surface of the condenser to the liquid [10].

Direct modification of the condenser to bring the condenser return pipe into the liquid would have been difficult since the condensate return surrounds the gas inlet. A pipe was therefore installed beneath the outlet of the condenser with an end-section filled with stainless steel wool enclosed by sintered metal discs, the idea being to discharge any ions. This addition to the system allowed for closed-system drift lifetimes of several milliseconds. There was, however, still some uncertainty in our minds about the action of this new feature. To confirm that ions were indeed the impurity introduced during condensing, the steel wool and sintered metal section of the return pipe was replaced with a section containing an electrically isolated metal rod at its center with an electrical connection to the outside of the cryostat. With a potential difference of $1 \frac{1}{2} \mathrm{kV}$ between the rod and the pipe, any argon ion would have plenty of time to reach an electrode given the flow rate of the condensate through the pipe and the pipe diameter.

In practice we observed very little difference in drift lifetime whether the rod was set to be a cathode, or an anode, or grounded directly to the cryostat, implying that the effect of the steel wool and sintered metal was not due to discharging ions. When the steel wool was examined under a microscope to see if the effect was from trapping some particulate, it was pristine - suggesting that if the metal was trapping something, the trapped material had evaporated when warmed to room temperature.

\subsection{Characterization of Condensing-Associated Impurities with Return Paths}

A mechanism, detailed in Figure 4, was installed beneath the outlet of the condenser and allowed one of four return paths for condensate return.

The different return paths were chosen for their ability to remove ions or particulate from the condensate. The thin, spiraled tube was designed to stop condensed argon from dripping into the bulk liquid and so prevent the generation of ions. The sintered glass was chosen for its ability to remove particulate, but not discharge any ions generated as the condensate dripped from the condenser into the return path. The sintered metal and steel wool return was used because it had prior success at removing condensing-associated impurities (Section 3.1), presumably because it removed both ions and particulate. The hole was chosen to provide a baseline to which to compare the effects of the other return paths. The length of the sintered glass and sintered metal return tubes was chosen to allow the ends to be uncovered if the argon depth in the cryostat was below 18 inches - thus forcing the condensed argon once again to drip out of the return and splash into the liquid. 
The cryostat was initially filled with 29 out of 40 inches of argon, enough to cover the outlets of all the return paths except the hole. The effect of filtering the condensate through each of the returns was observed and results are shown in Figure 6.

To clarify the effects of the return paths and internal filter operation, the impurity concentration in the cryostat was modeled using three 'types' of impurities, each with different behavior. ${ }^{1}$

The first class of impurities, base impurities [I1], provides a fixed, minimum contaminant concentration that limits the maximum electron drift lifetime. This variable combines any non-ideal or not-understood behavior of the MTS into one quantity. The second class, condensing-independent impurities [I2], accumulates as surfaces release contaminants directly into the liquid. The third type, condensing-associated impurities [I3], accumulates at a rate proportional to condenser activity. The first class is simply a constant in time; see equation (1). The source of the second class of impurities is modeled to decrease in time similar to a surface under vacuum and these impurities are removed by the action of the internal filter; see equation (2). Condenser operation adds the third class of impurities to the liquid. The rate at which these condensing-associated impurities are added is affected by condensing rate and the return path in use, with the assumption that each path removes a fraction of the impurities from the condensate before returning it to the bulk liquid. Once in the liquid, these impurities are removed by internal filter operation and a passive (gettering) mechanism that is clearly present (see Figure 6). The time dependence of this third type of impurity is described in equation (3). The electron drift lifetime in milliseconds equals $1 /([I 1]+[I 2]+[I 3])$.

$$
\begin{gathered}
{[I 1]=\text { Base Impurities }} \\
\frac{d[I 2]}{d t}=(\text { Cond. Indep. Source }) / t^{1 / 2}-(\text { Int. Filter Rate }) \times[I 2] \\
\frac{d[I 3]}{d t}=(\text { Cond. Assoc. Source }) \times(1-\text { Frac. Removed by Return }) \\
-(\text { Int. Filter Rate }+ \text { Gettering Rate }) \times[\text { I3 }]
\end{gathered}
$$

Table 1 gives the parameters of the model and their values as measured directly where possible or as found using a least-squares fit to the observed electron drift lifetimes. From the fit we see that the return path with sintered metal and steel wool removed a large fraction $(\approx 90 \%)$ of the condensing-associated impurities; the performance of the other returns did not conclusively distinguish between ions or particulate. Our preferred explanation is that the condensingassociated impurities desorb from 'warm' metal surfaces, enter the argon vapor, and are mixed into the condensate and thus into the liquid by the action of the condenser. These impurities can exit the liquid argon by adsorbing to 'cold'

\footnotetext{
${ }^{1}$ The unit of impurity is inverse milliseconds.
} 

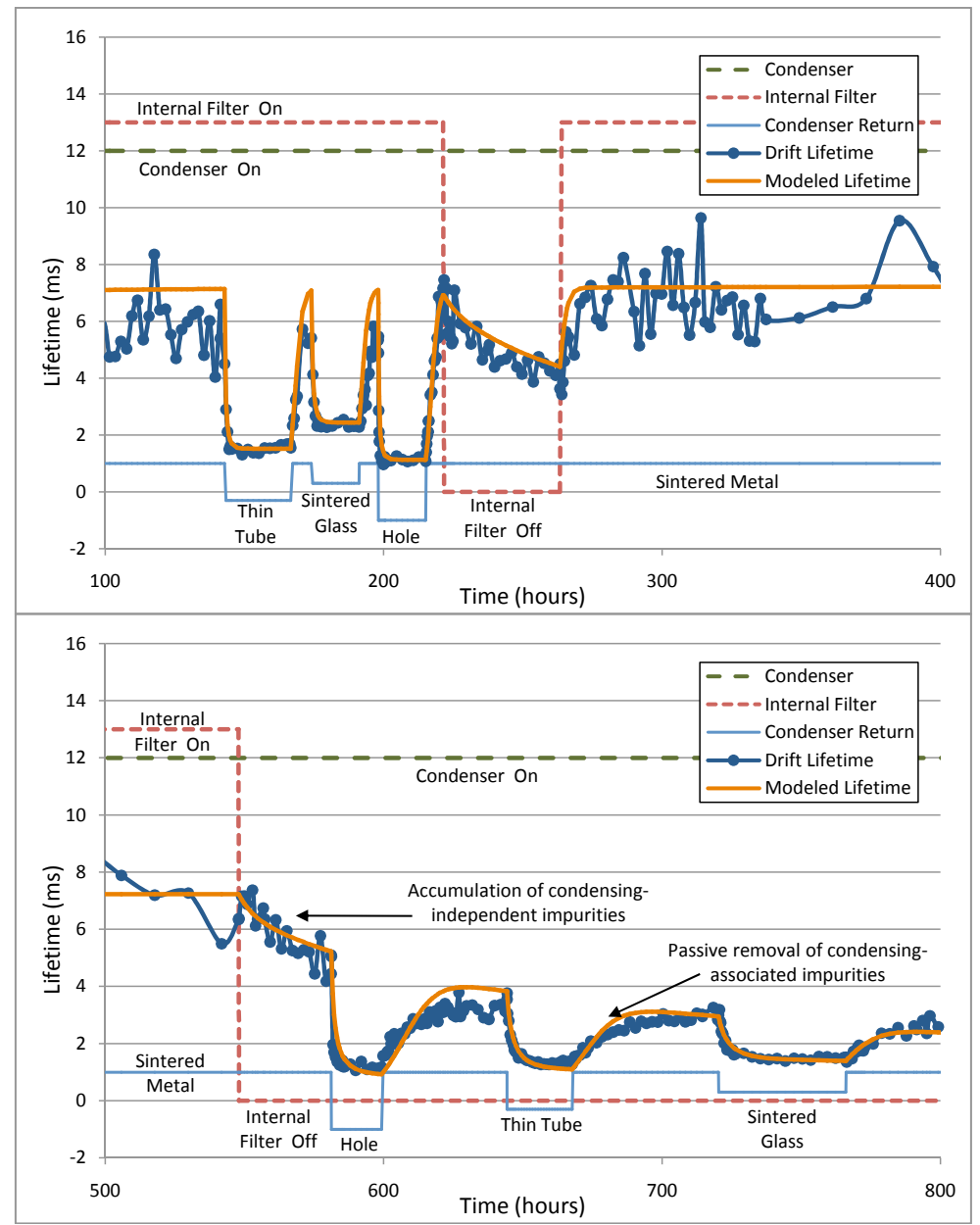

Figure 6: Electron drift lifetime as a function of condenser return path and internal filter operation. The dashed lines that start near the top of the first plot indicate the internal filter and the condenser operation: high for on, low for off. The line at the bottom with its associated labels indicates which condenser return was in use. The smooth line that covers the observed drift lifetime is the modeled drift lifetime. The figure shows the effect of the different return paths on the drift lifetime with the internal filter on (first part of Figure 6) and off (second part of Figure 6). For reference, when the condenser is off, the drift lifetime is $10-20 \mathrm{~ms}$. 


\begin{tabular}{|c|c|c|c|c|}
\hline \multicolumn{2}{|l|}{ Constant } & Value & Units & Comment \\
\hline \multicolumn{2}{|c|}{ Base Impurities } & 0.07 & & $\begin{array}{l}\text { Determined from drift } \\
\text { lifetime while venting with } \\
\text { internal filter on. }\end{array}$ \\
\hline \multicolumn{2}{|c|}{$\begin{array}{l}\text { Condensing-Independent } \\
\text { Source }\end{array}$} & 0.027 & $1 /$ hour & Determined from fit. \\
\hline \multicolumn{2}{|c|}{$\begin{array}{l}\text { Condensing-Associated } \\
\text { Source }\end{array}$} & $\begin{array}{l}0.16 \text { or } \\
0.64\end{array}$ & 1/hour & $\begin{array}{l}0.16 \text { if int. filter is off, } 0.64 \\
\text { if on. Ratio determined by } \\
\text { condenser LN2 consumption. }\end{array}$ \\
\hline \multirow{4}{*}{$\begin{array}{l}\text { Fraction } \\
\text { Removed } \\
\text { by Return }\end{array}$} & Hole & 0 & & Defined as zero. \\
\hline & Thin Tube & 0.28 & & Determined from fit. \\
\hline & $\begin{array}{l}\text { Sintered } \\
\text { Glass }\end{array}$ & 0.58 & & Determined from fit. \\
\hline & $\begin{array}{l}\text { Sintered } \\
\text { Metal }\end{array}$ & 0.92 & & Determined from fit. \\
\hline \multicolumn{2}{|c|}{ Internal Filter Rate } & 0.63 & $1 /$ hour & $\begin{array}{l}\text { Determined from internal } \\
\text { filter rate }\end{array}$ \\
\hline \multicolumn{2}{|c|}{ Gettering Rate } & 0.16 & 1/hour & Determined from fit. \\
\hline
\end{tabular}

Table 1: Constants for modeled impurity concentrations in the liquid of the MTS cryostat. Some values of the parameters were estimated from operational measurements; others were determined from a least-squares fit to the observed electron drift lifetimes.

metal surfaces. Return path behavior depends only on the amount of cold metal surface area presented to the condensate. This explanation accounts for differences in return path performance and also accounts for the passive removal of condensing-associated impurities from the bulk liquid as they attach to the walls of the cryostat.

As a check on this explanation, the amount of cold metal surface area presented by the return paths to the condensate was decreased by lowering the liquid level in the cryostat to 16 inches, thus fully exposing the return paths to the vapor region of the cryostat. The return paths removed fewer condensingassociated impurities in this new operating condition, as shown in Table 2. The continued success of the sintered metal and steel wool return in this condition also eliminates the possibility of ions as the condensing-associated impurity since with the lower level of argon in the cryostat, ions would have been generated as the condensate dripped from the sintered metal return into the bulk liquid and decreased the electron drift lifetime - an effect which was not observed.

\subsection{Water as a Candidate for the Condensing-Associated Impurity}

Condensing-associated impurities that appear in the liquid are removed by the internal filter. This suggests that the argon cannot be the long-term source of these impurities. Since the cryostat is evacuated before filling with argon, the source is unlikely to be in the gas phase. Water, however, is well known to remain on metal surfaces in vacuum [11] and has an affinity for cold surfaces. 


\begin{tabular}{|lllll|}
\hline Return Filter & $\begin{array}{l}\text { Cold Metal Surface } \\
\text { Area Presented to } \\
\text { Condensate }\left(\mathbf{c m}^{2}\right)\end{array}$ & Drift Lifetime (ms) \\
& 29" LAr & $16 " L A r$ & $29 " ~ L A r$ & $16 " ~ L A r$ \\
\hline Hole & 0 & 0 & 1.1 & 1 \\
\hline Thin Tube & 150 & 70 & 1.5 & 1.3 \\
\hline Sintered Glass & 300 & Near 0 & 2.4 & 1.2 \\
\hline Sintered Metal & $\approx 5000$ & $\approx 5000$ & 5 to 8 & 5 to 8 \\
\hline N/A (Venting) & N/A & N/A & $10-20$ & $10-20$ \\
\hline
\end{tabular}

Table 2: Electron drift lifetime as related to return path and liquid level. The sintered glass return path had less metal surface area that contacted the condensate and removed fewer impurities at the lower liquid level. This supports the explanation that return path performance depends on the amount of cold metal surface area presented to the condensate.

In order to further investigate the effect of water, a moisture analyzer [12] with a $2 \mathrm{ppb}$ detection limit and a $1 \mathrm{ppb}$ resolution was acquired to monitor the water concentration in the MTS cryostat. The argon vapor was monitored for moisture content because the moisture analyzer was not sensitive to concentrations in the liquid. For example, when using the sintered metal return and operating the internal filter, we estimate the water concentration in the liquid is $\approx \frac{1}{500}$ of that in the vapor. The sintered metal leaves only $\frac{1}{10}$ of the impurities in the condensate; this ratio is further reduced by the internal filter, which filters liquid 50 times faster than the condenser adds liquid.

To see the effect of additional warm metal surface area on the electron drift lifetime, the airlock volume was evacuated and then connected to the cryostat volume. The water concentration in the argon vapor was monitored while the internal filter and condenser were operated and the condensate passed through the sintered metal return. Results are shown in Figure 7. The water concentration in the argon vapor increases when the airlock is connected to the cryostat and this concentration is also an indicator of drift lifetime in that the product of the drift lifetime and water concentration remains roughly constant-providing initial indication that water may be the condensing-associated impurity.

\section{Material Tests and the Effect of Water on Electron Drift Lifetime}

A number of material tests, summarized in Table 3, have been performed to determine the effect of various materials on the electron drift lifetime and the role of water. Test materials were inserted into the sample cage in the airlock and then purged with argon from the cryostat; evacuation was occasionally used where noted. The cage with the material was then lowered into the liquid argon and subsequently raised into vapor. The RTD attached to the platform supporting the cage recorded the temperature of the sample. The drift lifetime was monitored throughout the process. The internal filter and condenser were operating continuously during these tests and the condensate passed through the sintered metal return. 


\begin{tabular}{|c|c|c|c|c|c|}
\hline \multirow[t]{2}{*}{ Material } & \multirow{2}{*}{$\begin{array}{l}\text { Sample } \\
\text { Surface } \\
\text { Area } \\
\left(\mathrm{cm}^{2}\right)\end{array}$} & \multicolumn{3}{|c|}{$\begin{array}{c}\text { Effect of Material on } \\
\text { Electron Drift Lifetime (LT) }\end{array}$} & \multirow[t]{2}{*}{ Comments } \\
\hline & & $\begin{array}{l}94 \mathrm{~K} \\
\text { liquid }\end{array}$ & $\begin{array}{l}\approx 120 \mathrm{~K} \\
\text { vapor }\end{array}$ & $\approx 225 \mathrm{~K}$ Vapor & \\
\hline $\begin{array}{l}\text { Red-X } \\
\text { Corona Dope }\end{array}$ & 100 & None & None & $\begin{array}{l}\text { LT Reduced from } \\
8 \text { to } 1 \mathrm{~ms} ; \\
\text { recovery observed. }\end{array}$ & $\begin{array}{l}\mathrm{H}_{2} \mathrm{O} \text { concentration } \\
\text { not monitored. }\end{array}$ \\
\hline Deactivated & 200 & None & Not & LT reduced from & $\mathrm{H}_{2} \mathrm{O}$ concentration \\
\hline Rosin Flux ${ }^{b}$ & & & Tested & $\begin{array}{l}8 \text { to } 1.5 \mathrm{~ms} \\
\text { recovery observed }\end{array}$ & not monitored. \\
\hline FR4 & 1000 & None & $\begin{array}{l}\text { Not } \\
\text { Tested }\end{array}$ & $\begin{array}{l}\text { LT reduced from } \\
8 \text { to }<1 \mathrm{~ms}\end{array}$ & $\begin{array}{l}\text { Outgassed enough } \mathrm{H}_{2} \mathrm{O} \\
\text { at } 225 \mathrm{~K} \text { to saturate } \\
\text { sintered metal return. }\end{array}$ \\
\hline Taconic $^{c}$ & 600 & None & $\begin{array}{l}\text { Not } \\
\text { Tested }\end{array}$ & LT reduced. & $\begin{array}{l}\text { Sample outgases water } \\
\text { at } 225 \mathrm{~K} \text {. }\end{array}$ \\
\hline $\begin{array}{l}\text { Hitachi } \\
\mathrm{BE} 67 \mathrm{G}^{d}\end{array}$ & 300 & None & $\begin{array}{l}\text { Not } \\
\text { Tested }\end{array}$ & $\begin{array}{l}\text { LT reduced; } \\
\text { recovery observed }\end{array}$ & $\begin{array}{l}\text { Sample outgases water } \\
\text { at } 225 \mathrm{~K} \text {; outgassing } \\
\text { reduced over time. }\end{array}$ \\
\hline TacPreg $^{e}$ & 200 & None & None & $\begin{array}{l}\text { LT reduced; } \\
\text { recovery observed }\end{array}$ & $\begin{array}{l}\text { Sample outgases water } \\
\text { at } 225 \mathrm{~K} \text {; outgassing } \\
\text { reduced over time. }\end{array}$ \\
\hline $\begin{array}{l}\text { FR4, y-plane } \\
\text { wire endpoint } \\
\text { for uBooNE }\end{array}$ & 225 & None & None & $\begin{array}{l}\text { LT reduced from } \\
8 \text { to } 3 \mathrm{~ms}\end{array}$ & $\begin{array}{l}\text { Sample outgases water } \\
\text { at } 225 \mathrm{~K} \text {. }\end{array}$ \\
\hline $\begin{array}{l}\text { FR4, y-plane } \\
\text { wire endpoint } \\
\text { for uBooNE }\end{array}$ & 225 & None & None & None & $\begin{array}{l}\text { Sample was evacuated } \\
\text { in airlock prior to } \\
\text { testing }\end{array}$ \\
\hline $\begin{array}{l}\text { FR4, y-plane } \\
\text { wire cover } \\
\text { for uBooNE }\end{array}$ & 225 & None & None & None & $\begin{array}{l}\text { Sample was evacuated } \\
\text { in airlock prior to } \\
\text { testing }\end{array}$ \\
\hline $\begin{array}{l}\text { Devcon 5-min } \\
\text { epoxy }\end{array}$ & 100 & None & None & $\begin{array}{l}\text { LT reduced from } \\
10 \text { to } 6 \mathrm{~ms} \text {; some } \\
\text { recovery observed }\end{array}$ & $\begin{array}{l}\text { Sample outgases water } \\
\text { at } 225 \mathrm{~K} \text {. }\end{array}$ \\
\hline
\end{tabular}

${ }^{a}$ GC Electronics, Part \# 10-5002

${ }^{b}$ Kester Soldering Flux, Formula \#1587, heated to approximately $450 \mathrm{~F}$ for 1 minute.

${ }^{c}$ Taconic \#TPG-30-0045-35, Grade TPG-30, Lot \#CBD7002 107053001

${ }^{d}$ Fiberglass laminate of non-halogenated material.

${ }^{e}$ Taconic \#TLG-30-0600-HH/HH, Lot \#10707111B, copper cladding mechanically removed from one side.

Table 3: Summary of material test results. Materials were inserted into the liquid argon and then raised into the argon vapor. The water concentration in the argon vapor, the electron drift lifetime, and the sample temperature were monitored during material tests. No effects on the electron drift lifetime were seen with any of the materials while they were immersed in liquid. Most materials began outgassing water and reduced the drift lifetime when raised to $225 \mathrm{~K}$. The outgassing decreased for some materials after some days and there was a corresponding increase in the drift lifetime. For all tests with water concentration data, the drift lifetime was related to the water concentration by (Drift Lifetime in $\mathrm{ms}) \times\left(\mathrm{H}_{2} \mathrm{O}\right.$ Concentration in $\left.\mathrm{ppb}\right) \approx 17$. 


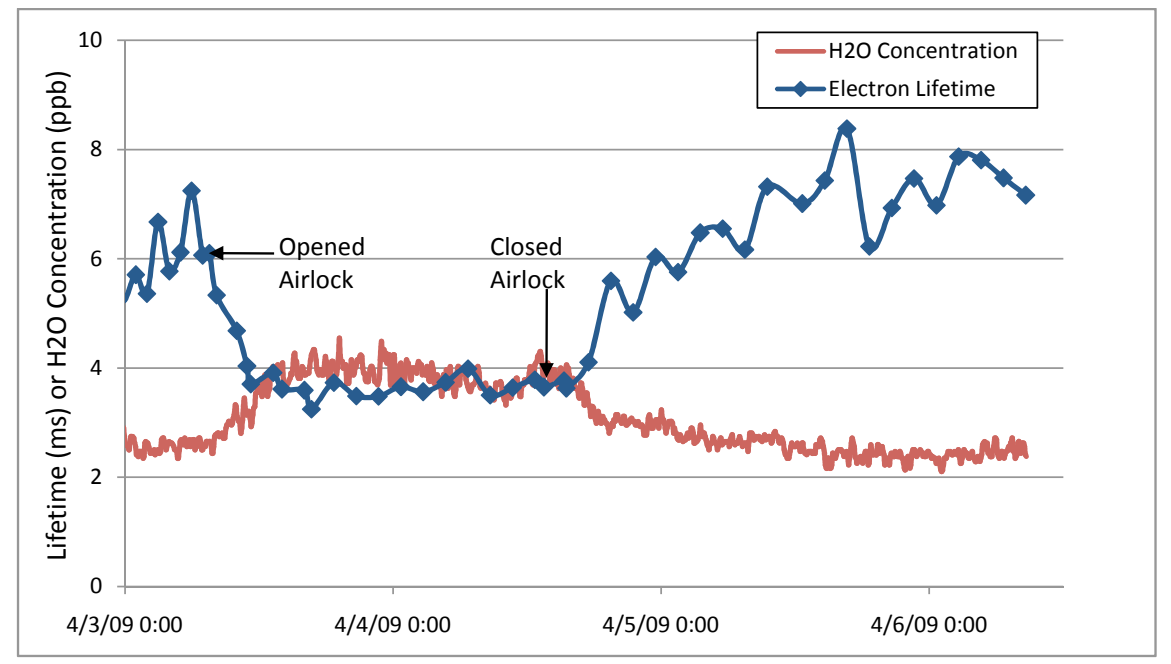

Figure 7: Effect of connecting cryostat and airlock volumes. The cryostat was connected to the airlock by opening the gate valve that typically separates the two. Prior to opening, the airlock was under vacuum. The increase in water concentration is attributed to the additional warm metal surface area in contact with the argon vapor. The relationship between water concentration and drift lifetime is similar to the relationship observed during materials testing (e.g. Figure 8). This test was performed with 15 inches LAr in the cryostat.

In general, none of the materials affected the drift lifetime when immersed in the liquid. When in the warmer regions of the vapor space, however, most materials produced an increase in the water concentration in the argon vapor, e.g. as shown in Figure 8. It was noted that the water concentration was correlated with the electron drift lifetime in a way similar to that observed when the cryostat and airlock volumes were connected. The product of the drift lifetime and the water concentration was a constant, independent of material: (Drift Lifetime in $\mathrm{ms}) \times\left(\mathrm{H}_{2} \mathrm{O}\right.$ Concentration in $\left.\mathrm{ppb}\right) \approx 17$. The actual increase in water concentration did depend on the material and on its preparation before insertion. As an example, after evacuation in the airlock for a few days prior to testing, PC board materials had little effect on the water concentration in the argon vapor and hence little effect on the drift lifetime as shown in Figure 9. These observations suggest that water may be the only significant contaminant introduced by materials.

\section{Summary and Conclusions}

We have built a system (the MTS) to test materials for use in a large liquid argon TPC. We have tested a number of materials commonly used in detector construction and found that when inserted into the liquid argon they have very little effect on the electron drift lifetime. This is encouraging for the construction 


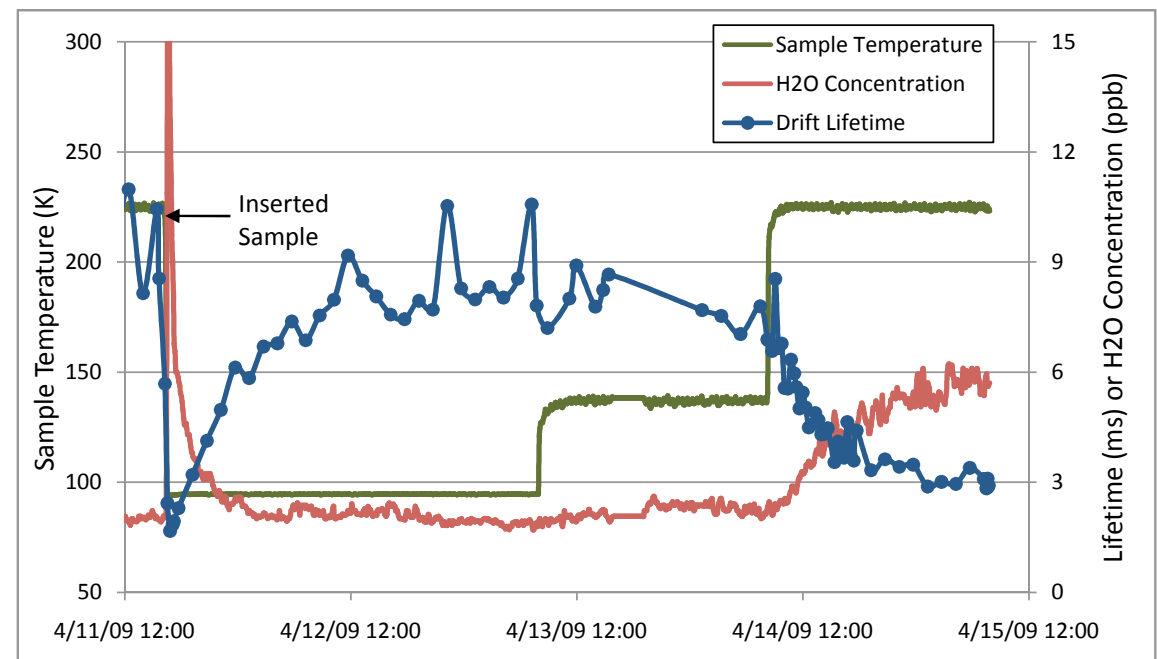

Figure 8: Material test of FR4 MicroBooNE y-plane wire endpoint. The sample was first lowered into the liquid argon then raised into the vapor so that the temperature of the sample was increased. When moved to $225 \mathrm{~K}$, the sample began to outgas and the effect on water concentration and drift lifetime can be seen in the figure. A similar relationship between water concentration and drift lifetime was observed during other material tests, including the metal surface area test documented in Figure 7. The material test was performed with 17 inches LAr in the cryostat. 


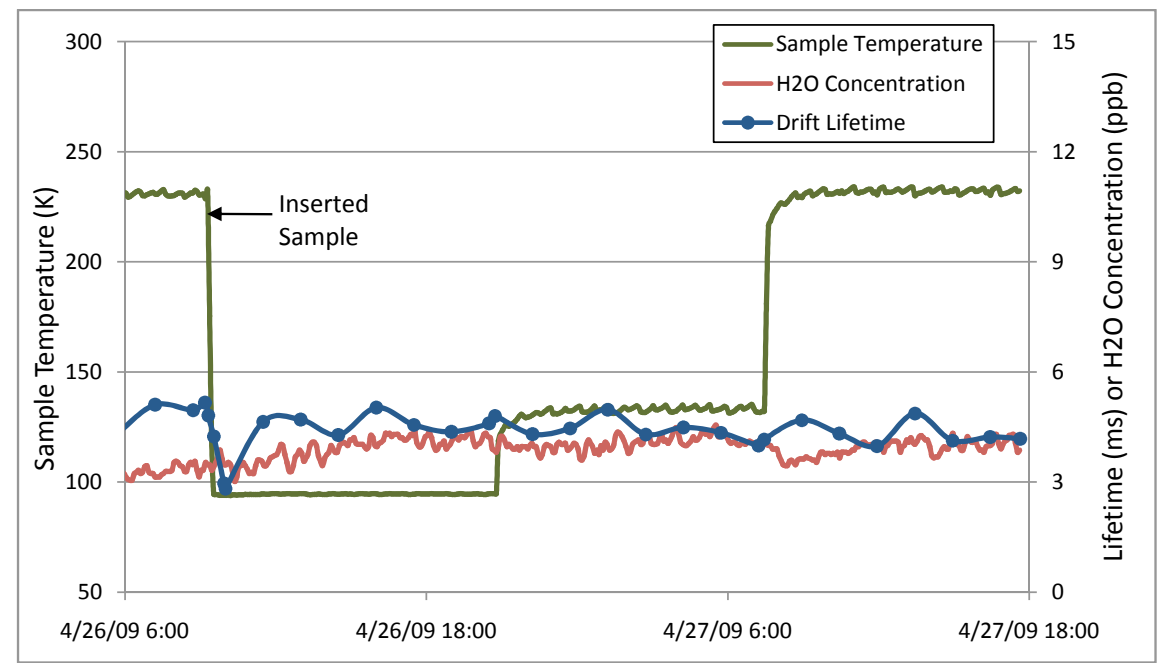

Figure 9: Material test of FR4 MicroBooNE y-plane wire endpoint prepared by evacuation. The sample was placed in the airlock and evacuated to $1 \mathrm{~m}$ Torr for a few days prior to testing. The sample did not outgas any water during testing and had no effect on the drift lifetime. The material test was performed with 13 inches LAr in the cryostat. Relative to the test documented in Figure 8, the level of water vapor in the system was higher and the drift lifetime correspondingly lower. We attribute this to the lower level of argon in the cryostat.

of liquid argon-based detectors. We have observed a direct relation between the water concentration in the vapor above the liquid argon and the electron drift lifetime of the form (Drift Lifetime $) \times($ Water Concentration $)=$ Constant. The water concentration in the vapor space can be affected by introducing materials into the vapor space and we find that the constant in the expression above is independent of material. This leads us to conclude that the major contaminant in our system is water. We have not directly measured water concentrations in the liquid but we infer from measurements of the water concentration in the vapor space that concentrations of water at the level of ten parts per trillion affect the drift lifetime, and that the concentration of water in the liquid effectively limits the electron drift lifetime.

We have demonstrated - something we did not intend - that a system design with a condenser returning condensate directly into the bulk liquid is not viable if there are warm surfaces open to the argon vapor. While we have achieved drift lifetimes of more than 10 milliseconds with an open system the lifetimes we have achieved with our closed system using the return path mechanism do not exceed 8 milliseconds. With an open system, any water released from warm metal surfaces or from warm materials in the vapor space does not enter the liquid argon. The operation of our condenser, however, very effectively introduces the water-contaminated argon vapor into the liquid of the cryostat. We find that exposing the condensate to a large cold metal surface before entry 
to the bulk liquid removes most of the water from the condensate, and allows our system to function effectively for testing materials.

\section{Acknowledgments}

The present effort to understand liquid argon as a detection material for particle physics is inspired by the work of the ICARUS collaboration [1]. Recent work on liquid argon TPCs at Fermilab was initiated by Adam Para. We are happy to acknowledge the help of John Krider in all aspects of the initial stages of this project and of Ewa Skup in operations and with the construction of lifetime monitors. Alan Baumbaugh provided the lifetime monitor data acquisition which allows the system to run unattended. Particularly useful have been the electronic logbook and the document database systems provided by Suzanne Gysin and Marcia Teckenbrock of the Fermilab Computing Division. This work was carried out under DOE contract DE-AC02-07CH11359.

\section{References}

[1] S. Amerio et al., Nucl. Inst. Meth. A 527 (2004) 329-410.

[2] D. Finley et al., FERMILAB-FN-0776-E (2005).

[3] A. Curioni et al., Nucl. Instr. Meth. A 605 (2009) 306-311.

[4] T. Tope, Valve and Instrument List, Fermilab LArTPC Document Database: lartpc-docdb.fnal.gov/cgi-bin/ShowDocument?docid=440.

[5] FNAL, Subcontract \#560637 with Airgas, Liquid argon minimum purity 99.997\%.

[6] Sigma-Aldrich Corporation, Molecular Sieve Type 4A.

[7] Engelhard Corporation, MSDS for Cu-0226 $14 \times 20$ (2002).

[8] D. Finley et al., FERMILAB-TM-2385-E (2006).

[9] G. Carugno et al., Nucl. Instr. Meth. A 292 (1990) 580.

[10] P. Hirsch, Electrostatic Charge Generation in Hydrocarbon Liquids, Master's thesis, MIT (1979).

[11] R. Dobrozemsky, S. Menhart, K. Buchtela, J. Vac. Sci. Technol. A 25 (2007) $551-556$.

[12] Tiger Optics, LLC, HALO CRDS Moisture Analyzer. 